\title{
Management of gastroesophageal reflux disease in adults: a pharmacist's perspective
}

This article was published in the following Dove Press journal: Integrated Pharmacy Research and Practice

\author{
Brett MacFarlane ${ }^{1,2}$ \\ 'Australian College of Pharmacy, \\ Canberra, ACT, Australia; ${ }^{2}$ Faculty \\ of Health, Queensland University of \\ Technology, Brisbane, QLD, Australia
}

Correspondence: Brett MacFarlane Australian College of Pharmacy, 9/65 Tennant St, Fyshwick, ACT 2609, Australia

Tel +6I 261884320

Email brett.macfarlane@acp.edu.au

\begin{abstract}
Gastroesophageal reflux disease (GERD) is a common gastrointestinal diagnosis, a leading reason for endoscopy and cause of potentially serious complications, resulting in significant individual and system-wide health burden. Approximately one quarter of people living in western countries have experienced GERD, and the prevalence appears to be on the rise. Risk factors for GERD include hiatus hernia, obesity, high-fat diet, tobacco smoking, alcohol consumption, pregnancy, genetics, and some medications. The cardinal symptoms of GERD are troublesome heartburn and regurgitation. GERD is identified by taking a patient-centered history and if necessary can be classified by endoscopic investigation. The role of the pharmacist in the management of GERD is to confirm the diagnosis by history taking, confirm there are no alarming signs or symptoms that require referral to a doctor, and recommendation of short-term therapy to control symptoms. Effective pharmacological treatments for GERD include antacids, alginate, histamine $\mathrm{H} 2$ receptor antagonists, and proton pump inhibitors. This narrative review includes a comparison of the efficacy and safety of these treatments and pertinent information to help pharmacists advise patients with GERD on their appropriate use.
\end{abstract}

Keywords: GERD, GORD, reflux, pharmacist, PPI

\section{Introduction}

Gastroesophageal reflux disease (GERD) is a disorder of gastrointestinal motility associated with reflux of stomach contents into the esophagus and oral cavity. ${ }^{1}$ It is identified when reflux of stomach contents cause troublesome symptoms and/or complications. ${ }^{2}$

GERD is characterized by two cardinal esophageal symptoms: ${ }^{1}$ ) heartburn (reflux); and 2) regurgitation. Extra-esophageal symptoms such as non-cardiac chest (epigastric) pain, dental erosion, cough, laryngitis, and asthma are associated with, but are not specific for, GERD. GERD is also commonly associated with lower quality of life, poor quality of sleep and decreased work productivity. Complications of GERD include reflux esophagitis (most common), esophageal stricture, Barrett's esophagus, and esophageal adenocarcinoma. ${ }^{1,2}$

Safe and effective treatments for GERD include medications, diet, lifestyle adjustment and in some cases surgery. Medications can be accessed over-the-counter for short-term management or by doctor prescription for long-term management. Pharmacists can advise patients on appropriate use of GERD medications and help address their adverse reactions and drug interactions. 


\section{Epidemiology of GERD}

GERD is common, particularly in western countries. In the United States, GERD is the most frequent diagnosis of gastrointestinal origin and the most frequent indication for endoscopy. Therefore, GERD represents a significant concern in terms of burden on both the individual and the wider health system. ${ }^{3}$

The exact prevalence of GERD is difficult to determine due to the potential for patient self-treatment and variation in diagnostic practices and definitions for GERD. ${ }^{1}$ Epidemiological data indicate a prevalence of GERD of up to $27.8 \%$ in the United States and $25.9 \%$ in Europe. The prevalence of GERD in Japanese adults has been found to be as low as $11.6 \%{ }^{4}$

The prevalence of GERD seems to be rising. The longitudinal HUNT study in Norway found that the prevalence of at least weekly symptoms of GERD increased from $12 \%$ in 1995 to $17 \%$ in $1997 .{ }^{5}$ There is also evidence that GERD prevalence in Japan is on the increase. ${ }^{6}$

In North America, it is estimated that $19.8 \%$ of people have at least weekly symptoms of GERD, compared to $15.2 \%$ in Europe, $14.4 \%$ in the Middle East, and only 5.2\% in East Asia. ${ }^{7}$ In Australia, $11.3 \%$ of patients visiting a general practitioner had GERD of chronic duration. ${ }^{8}$

Studies indicate that the prevalence of new onset GERD, the severity of GERD, and the use of medications to treat symptoms of GERD tend to increase in older people. However, with many studies showing no increase, the evidence supporting an association between GERD and aging is conflicting. ${ }^{7,9}$ Evidence does indicate that the prevalence of GERD is increasing in younger people (adolescents and pediatrics), focusing attention on unhealthy dietary patterns and increasing obesity in the young. ${ }^{10}$

The incidence of GERD complicated by stricture rose throughout the 1980s and early 1990s however decreased in the 21st century. This decrease seems to align with the introduction of proton pump inhibitor (PPI) therapy. ${ }^{7}$ The incidence of premalignant Barratt's esophagus has seen a recent dramatic increase; however, this may be due to changes in diagnostic practices rather than alteration in risk profile. The incidence of the most concerning GERD complication, esophageal adenocarcinoma, continues to rise dramatically.,11 Data analysis indicates that this rise is a true increase in disease burden and not due to overdiagnosis or reclassification. Esophageal adenocarcinoma is the fastest rising malignancy in the United States, yet it remains relatively rare. ${ }^{11}$
Some studies have indicated that GERD symptoms are more prevalent in males than females; however, evidence is conflicting and predominance in males cannot be reliably determined based on current data. Complications from GERD do appear to be more prevalent in males.?

\section{Risk factors for reflux development}

Many potential risk factors are associated with the development of GERD, which are discussed in Table $1 .{ }^{12-19}$

\section{GERD and the postprandial gastric acid pocket}

The postprandial gastric acid pocket was first reported by Fletcher et $\mathrm{al}^{20}$ in 2001. Evidence from $\mathrm{pH}$ studies indicated that the $\mathrm{pH}$ of the region just below the lower esophageal sphincter (LES) was lower than that of the stomach, occasionally after a meal, despite the normal buffering effect of food. ${ }^{20}$

It was identified that a postprandial gastric acid pocket containing unbuffered, extremely low $\mathrm{pH}$ (2) contents, accumulates at the top of the stomach contents (normal $\mathrm{pH}$ 4-5), 10-15 minutes after eating. This occurs when gastric juices do not mix properly with the meal, so that it floats at the top of the stomach contents to form a layer that can persist for up to 2 hours. Compared to healthy controls, people with GERD tend to produce a larger acid pocket, which floats higher into the gastroesophageal junction (allowing for more occurrences of reflux), has a lower $\mathrm{pH}$, and lasts for longer. ${ }^{20,21}$ The acid pocket contributes more to symptoms if the patient lies down after eating and in people with hiatus hernia. ${ }^{20}$

\section{LES function}

The function of the LES is also an important factor for GERD. The symptoms of GERD predominantly occur during periods of transient lower esophageal sphincter relaxations (TLESRs) which occur in all people. TLESRs last for 10-45 seconds, to allow the stomach to vent gases during belching. People with GERD symptoms do not experience a higher frequency of TLESRs than people without symptoms; however, they are more likely to experience GERD symptoms during a TLESR. Also the positioning of the acid pocket is relevant to GERD symptoms. More frequent symptoms occur during TLESRs with acid pockets situated above the diaphragm compared to acid pockets situated below. ${ }^{12}$ 
Table I Description of risk factors for gastroesophageal reflux disease (GERD) development

\begin{tabular}{|c|c|}
\hline GERD risk factors & Description \\
\hline Hiatus hernia & $\begin{array}{l}\text { Hiatus hernia results from the displacement of the junction between the esophagus and the stomach (the } \\
\text { gastroesophageal junction) which normally acts as a barrier to reflux of stomach contents into the esophagus. Hiatus } \\
\text { hernia is likely to be caused by weakening or rupture of the phrenoesophageal ligament. Patients with hiatus hernia have } \\
\text { more episodes of reflux and more severe reflux esophagitis }\end{array}$ \\
\hline Obesity & $\begin{array}{l}\text { People who are overweight or obese (particularly with central adiposity) have a higher risk of developing GERD, erosive } \\
\text { esophagitis, Barrett's esophagus, and esophageal adenocarcinoma. Central adiposity increases gastric pressure, thus } \\
\text { altering the pressure gradient across the gastroesophageal junction, which favors the development of reflux. Obese } \\
\text { people are also more likely to develop hiatus hernia, leading to GERD }\end{array}$ \\
\hline High-fat diet & $\begin{array}{l}\text { Patients with GERD experience more episodes of reflux following consumption of a high-fat meal compared to a low-fat } \\
\text { meal }\end{array}$ \\
\hline Tobacco smoking & $\begin{array}{l}\text { There are many studies linking tobacco smoking to the development of GERD. Increased GERD risk is evident in current } \\
\text { and former smokers. The risk of GERD increases with the duration of smoking as well as the amount of tobacco smoked }\end{array}$ \\
\hline Alcohol consumption & $\begin{array}{l}\text { Mainly, alcohol consumption is not associated with an increased risk of GERD. This is based on a number of very large } \\
\text { cohort studies. However, some evidence does indicate that moderate to high alcohol consumption ( }>7 \text { alcoholic drinks } \\
\text { per week) may increase GERD risk }\end{array}$ \\
\hline $\begin{array}{l}\text { Helicobacter pylori } \\
\text { infection }\end{array}$ & $\begin{array}{l}\text { The link between } H \text {. pylori infection and development of peptic ulcer disease is now well accepted. Evidence also indicates } \\
\text { that } H \text {. pylori infection adds to the burden of nonsteroidal anti-inflammatory drug-associated GERD. Yet while diagnoses } \\
\text { of GERD are increasing, the rate of } H \text {. pylori infection is declining. An association between } H \text {. pylori and GERD symptoms } \\
\text { is tenuous, with many studies actually indicating a reduced risk of GERD in people infected with } H \text {. pylori. Also } H \text {. pylori } \\
\text { does not appear to be associated with the development of Barrett's esophagus or esophageal adenocarcinoma; however, } \\
\text { it is linked to gastric cancer. Evidence does not support } H \text {. pylori eradication therapy for GERD management }\end{array}$ \\
\hline Pregnancy & $\begin{array}{l}\text { GERD is reported by } 40 \%-85 \% \text { of pregnant women. It is most likely linked to increased progesterone causing relaxation } \\
\text { of the lower esophageal sphincter. Pregnancy can precipitate GERD symptoms or worsen existing GERD. Onset of GERD } \\
\text { is commonly toward the end of the first trimester and often lasts throughout the remainder of gestation, often worsening } \\
\text { with gestational age. Symptoms usually resolve after delivery. While symptoms can be severe, complications from GERD } \\
\text { during pregnancy are not likely to develop }\end{array}$ \\
\hline Genetics & $\begin{array}{l}\text { Evidence supports a genetic cause for GERD. Studies indicate a concordance rate of GERD between identical twins of } \\
43 \% \text { and for nonidentical twins of } 26 \% \text {. Genetic testing also suggests a possible link between GERD, Barrett's esophagus, } \\
\text { and esophageal adenocarcinoma }\end{array}$ \\
\hline Medications & $\begin{array}{l}\text { A number of medications can cause GERD symptoms and/or esophageal injury including: } \\
\text { Nonsteroidal antiinflammatory drugs, antibiotics (eg, tetracyclines and clindamycin), statins, angiotensin-converting } \\
\text { enzyme inhibitors, bisphosphonates, vitamin C, potassium, iron, clomipramine, quinidine, anticholinergics, tricyclic } \\
\text { antidepressants, corticosteroids (oral and inhaled), } \beta \text {-agonists, nitroglycerines, aminophylline, benzodiazepines, warfarin, } \\
\text { cyproterone, ethinylestradiol, and calcium channel blockers }\end{array}$ \\
\hline Other risks & $\begin{array}{l}\text { Consumption of coffee, chocolate, citrus products, tomato products, spicy foods, and carbonated beverages may increase } \\
\text { GERD risk }\end{array}$ \\
\hline
\end{tabular}

\section{GERD symptoms}

The cardinal esophageal symptoms of GERD are described in Table $2 .{ }^{2}$ The presence of heartburn (reflux) and regurgitation is characteristic of most cases of GERD; however, there is significant variability across studies. It is estimated that heartburn is experienced at least daily in $24 \%$ of people with GERD and once or twice weekly in $43 \%{ }^{22}$ It is generally accepted that predominance of either heartburn or regurgitation is sufficient for a GERD diagnosis. ${ }^{2}$

\section{GERD diagnosis and classification}

Endoscopic investigation can classify GERD pathology as erosive reflux disease (ERD) or non-erosive reflux disease (NERD). GERD can be subclassified into esophageal and extra-esophageal syndromes. ${ }^{1,2}$ Studies indicate that erosion can only be found in up to $25 \%$ of people with GERD symptoms. Therefore, the other $75 \%$ are classified as having NERD. It is estimated that $\sim 10 \%$ of people with NERD are misclassified due to healing of erosions by PPI therapy prior to endoscopy. ${ }^{10}$

If available, the diagnosis of NERD can be verified by performing gastric $\mathrm{pH}$ studies, which can identify excess acid and correlate symptoms with episodes of reflux. In simpler empiric terms, NERD can be verified by trialing acid suppressive therapy, whereby relief from symptoms supports the diagnosis. Inability of acid suppressive therapy to control symptoms can point to a diagnosis of functional dyspepsia (FD). ${ }^{10}$

Due to limited access to and lack of diagnostic sensitivity of endoscopic investigation, most GERD diagnoses in 
Table 2 Description of the cardinal gastroesophageal reflux disease (GERD) symptoms

\begin{tabular}{ll}
\hline GERD symptom & Description \\
\hline Heartburn (reflux) & $\begin{array}{l}\text { Retrosternal (behind the breastbone) burning } \\
\text { sensation } \\
\text { Understanding of the term "heartburn" is open } \\
\text { to interpretation and is not as descriptive as "a } \\
\text { burning sensation behind the breastbone" } \\
\text { Relieved by simple antacids } \\
\text { Back flow of gastric contents into the mouth or } \\
\text { hypopharynx } \\
\text { Distinguished from back flow of gastric } \\
\text { contents into the lower esophagus which is a } \\
\text { common and often inconsequential occurrence }\end{array}$ \\
\hline
\end{tabular}

clinical practice are based on symptoms. In many cases, endoscopy does not discover the presence of esophageal injury in symptomatic patients (endoscopy negative reflux disease). In some cases, endoscopy can further characterize the condition by demonstrating a distinct esophageal pathology. Therefore, the classification of GERD covers many manifestations. The standard definition of GERD (the Montreal definition) allows for a presumptive GERD diagnosis to be made based on symptoms, without the need for endoscopy, and the final diagnosis can be made based on a positive trial of PPI therapy (note however that PPI therapy is not effective in all cases). ${ }^{1,2}$

Part of the GERD definition focuses on a subjective description of "troublesome" symptoms. Not all cases of reflux are troublesome, as they do not adversely affect an individual's well-being, for example, heartburn that occurs only once a week. Indeed many people experience completely asymptomatic instances of reflux. Whether reflux symptoms are troublesome or not should be determined by the patient, as there is a broad interindividual variability of impact of reflux on quality of life. Occurrences of reflux that are not troublesome to the patient should not be diagnosed as GERD. ${ }^{2}$

Conversely, asymptomatic complications associated with established esophageal injury, which for example can occur in reflux esophagitis and Barrett's esophagus are still considered to be GERD despite lack of overt symptoms. ${ }^{2}$

Therefore a GERD diagnosis can be made if:

- The patient describes symptoms as troublesome

- Complications are identified

- Improvement of symptoms with PPI adds weight to a GERD diagnosis

\section{FD}

The link between endoscopically determined esophagitis and dyspeptic symptoms is difficult to quantify. Only $\sim 13 \%$ of symptomatic patients show evidence of esophagitis on endoscopy. The only endoscopic finding that significantly contributes to dyspeptic symptoms is gastric ulcer, which only occurs in about $8 \%$ of people with dyspepsia. ${ }^{23}$

A potential diagnosis for patients with upper gastric symptoms, without apparent endoscopic pathology, is FD, which is one of the many functional gut disorders, now better described as disorders of gut-brain interaction. ${ }^{24}$

The symptoms of FD can be divided into two different syndromes. The more common postprandial distress syndrome (PDS) is associated with meal-related symptoms and characterized by postprandial fullness (abdominal fullness after eating) and early satiety (inability to finish a normalsized meal). The second, epigastric pain syndrome (EPS), is more closely related to symptoms of GERD and involves epigastric pain or burning. Other more unusual symptoms of FD include nausea, bloating, belching, and heartburn. It is estimated that over $40 \%$ of Americans have PDS and that this is commonly misdiagnosed as GERD. ${ }^{23}$

Although the pathophysiology of FD is not well understood, it has been associated with: ${ }^{23}$

- Immunological responses

- Eosinophil and mast cell invasion of the gastric mucosa

- Anxiety (often present prior to onset of dyspeptic symptoms)

- Altered gastric emptying (slow or rapid)

- Impaired gastric accommodation (reduced ability for the stomach to relax and expand during a meal)

- Microbial dysbiosis

- Visceral hypersensitivity (exaggerated visceral pain)

- Central dysregulation of gut signaling and motor function.

Treatment for EPS involves the use of acid suppressive therapy, whereas PDS is treated with prokinetic agents and sometimes tricyclic antidepressants, with a range of new treatments on the horizon. ${ }^{25}$

\section{Confirmation of GERD diagnosis by pharmacists}

In 2011, an expert panel of gastroenterologists published guidance for the use of over-the-counter PPIs for the treatment of GERD. The panel concluded that effective selfmanagement of reflux disease with over-the-counter PPIs could lead to lasting freedom from symptoms and improved quality of life for sufferers. ${ }^{26}$ 
The algorithm proposed that when pharmacists are addressing requests for treatment of GERD symptoms, they should do the following:

1. Confirm the GERD diagnosis based on the patient's symptomatic history

2. Rule out any reason for referral to a doctor (alarming symptoms)

3. Focus on the nature, severity, and frequency of symptoms when determining treatment.
Key questions to help confirm the GERD diagnosis and rule out a requirement for referral are summarized in Table 3 (based on Holtmann et $\mathrm{al}^{26}$ ).

\section{Alarming symptoms and complications}

In many cases, short-term pharmacotherapy for GERD symptoms will achieve acceptable benefit. However, in cases of complication, long-term pharmacotherapy and additional

Table 3 Questions pharmacists can ask to confirm the diagnosis of gastroesophageal reflux disease (GERD) and rule out any reason for doctor referral before over-the-counter treatment can be recommended

\begin{tabular}{|c|c|c|}
\hline GERD attribute & Question & Key responses \\
\hline Patient age & What is the age of the patient? & $\begin{array}{l}\text { First appearance of symptoms of GERD in older people ( }>65 \text { years) is } \\
\text { concerning and requires doctor referral }\end{array}$ \\
\hline \multirow[t]{9}{*}{ Symptoms } & What symptoms are you experiencing? & Burning sensation \\
\hline & & Beginning in the midpoint of the abdomen and rising toward the throat \\
\hline & & Rising of food into throat/mouth \\
\hline & Could you show me where the burning is occurring? & Patient indicates upward motion from abdomen/chest to throat \\
\hline & What worsens your symptoms? & Large meal \\
\hline & & Fatty meal \\
\hline & & Stooping/bending, etc \\
\hline & Are your symptoms bothersome? & Yes/no \\
\hline & How severe are your symptoms? & Mild/moderate/severe \\
\hline \multirow[t]{10}{*}{ Alarming symptoms } & Are you experiencing any other symptoms? & Darkened bowel motions \\
\hline & (It may be necessary for the pharmacist to list some & Vomiting blood \\
\hline & of these symptoms as the patient may not associate & Crushing chest pain \\
\hline & them with reflux) & Diagnosed/suspected anemia \\
\hline & & Frequent vomiting \\
\hline & & Weight loss \\
\hline & & Difficulty swallowing \\
\hline & & Severe abdominal pain \\
\hline & & Exercise-related symptoms \\
\hline & & Feeling full after eating small amounts \\
\hline \multirow[t]{4}{*}{ History } & How long have you had these symptoms? & Days/weeks/months/years \\
\hline & How often do you experience these symptoms? & $\leq 3$ times per week \\
\hline & & $>3$ times per week \\
\hline & & Daily \\
\hline \multirow[t]{2}{*}{ Comorbidities } & Do you have a history of any other health & Gastric ulcer \\
\hline & conditions? & Cancer \\
\hline \multirow[t]{4}{*}{ Family history } & $\begin{array}{l}\text { Have any of your parents or brothers and sisters } \\
\text { experienced similar symptoms? }\end{array}$ & Yes/no \\
\hline & What was their diagnosis? & GERD \\
\hline & & Reflux \\
\hline & & Gastrointestinal cancer \\
\hline Current medicines & $\begin{array}{l}\text { Do you take any prescription, over-the-counter, or } \\
\text { complementary medicines? }\end{array}$ & See Table I \\
\hline Other contributing & What other factors might be contributing to your & Stress \\
\hline \multirow[t]{2}{*}{ factors } & symptoms? & High coffee/alcohol intake \\
\hline & & Current or previous smoker \\
\hline \multirow[t]{4}{*}{ Previous treatment } & What treatment/s have you already tried? & Antacids/alginate \\
\hline & & Histamine $\mathrm{H} 2$ receptor antagonists \\
\hline & & Proton pump inhibitors \\
\hline & Were these effective? & Yes/no \\
\hline
\end{tabular}


treatment including surgery may be indicated. Esophageal complications of GERD include:

1. Reflux esophagitis

2. Esophageal stricture

3. Barrett's esophagus

4. Esophageal adenocarcinoma.

Reflux esophagitis is the most common of the GERD complications with $\sim 30 \%$ of people with GERD having erosive disease. ${ }^{10}$ Reflux esophagitis is due to inflammation caused by reflux of acid, bile salts, and pepsin from the gastric contents into the esophagus, leading to erosion of the esophageal mucosa. Historically thought to be due to acid "burning" the esophageal mucosa, recent evidence from a rat model and a small human study suggested that acid irritation leads to the release of proinflammatory cytokines that induce migration of inflammatory cells into the area, causing inflammation. ${ }^{27}$

Other causes of esophagitis not related to GERD include immune mediated, allergic, medication induced, and infectious. These potential causes should be investigated in patients with esophagitis without symptoms of reflux. ${ }^{28}$

Esophageal stricture is a narrowing of the lumen of the esophagus due to inflammation, fibrosis, or neoplasm. While stricture is a complication of GERD, up to $25 \%$ of people with stricture have no dyspeptic symptoms. Stricture causes dysphagia (particularly with solid foods), food impaction, odynophagia (painful swallowing), chest pain, and weight loss. Benign cases generally progress slowly (months to years) while malignant cases progress more quickly (weeks to months). ${ }^{29}$

Erosive esophagitis is an independent risk factor for the development of Barrett's esophagus (within 5 years), which is a precursor for esophageal adenocarcinoma. ${ }^{10}$ Therefore, it is highly desirable to prevent or control the formation of reflux esophagitis. ${ }^{27}$

Chronic inflammation due to reflux esophagitis can induce a process of cellular metaplasia whereby squamous esophageal mucosal cells are destroyed and replaced by gastric and intestinal columnar cells (Barrett's esophagus), leading to significantly increased risk of development of esophageal adenocarcinoma. The mechanism of metaplasia in Barrett's esophagus is not well understood. ${ }^{27}$

Estimates of the prevalence of Barrett's esophagus range from $5 \%$ to $15 \%$ of people with chronic GERD, with markedly higher rates of new diagnoses in men over 60 years. Only $\sim 0.4 \%-0.5 \%$ of people per year with Barrett's esophagus progress to esophageal adenocarcinoma; however, this represents a rapid increase in Western populations over the last few decades. ${ }^{10}$

\section{GERD treatment Diet and lifestyle modification}

The aim of the treatment for most patients with GERD is to control the symptoms. For the smaller cohort with severe or complicated disease, the aim is also to prevent and treat complications.

Mild, intermittent symptoms of GERD can be managed with diet and lifestyle modification alone, and these also form an important adjunct to pharmacotherapy for moderate to severe and complicated GERD. Diet and lifestyle modification involves identification and avoidance of precipitating factors including: ${ }^{30}$

- Eating smaller meals

- Avoiding problematic foods

- Avoiding high-fat foods

- Drinking fluids between and not during meals

- Avoiding lying down, bending/stooping, or going to bed soon after meals (within 2-3 hours)

- Avoiding eating before exercise

- Elevating the head of the bed (for nighttime symptoms)

- Lying on the left side of the body

- Quitting smoking

- Weight loss in both obese and healthy weight people (bariatric weight loss surgery has variable effects on GERD. Gastric bypass and gastric banding surgery has been shown to improve GERD symptoms; however, GERD can return within a few years of gastric banding. Gastric sleeve surgery can potentially precipitate GERD in people without preexisting symptoms).

\section{Pharmacotherapy of GERD}

Troublesome symptoms can be managed with medications, many of which are available without prescription. Medications for GERD symptoms include (Table 4):

- Antacids and alginate

- Histamine $\mathrm{H} 2$ receptor antagonists (H2RAs)

- PPIs

\section{Antacids and alginate}

A 2017 systematic review and meta-analysis found that alginate (commonly formulated in combination with antacids) is superior at improving GERD symptoms (either complete resolution or significant improvement) over antacids alone and also placebo, but not over H2RAs or PPIs (note that the 
Table 4 Treatments for gastroesophageal reflux disease (GERD) symptoms and their mechanisms of action

\begin{tabular}{|c|c|c|}
\hline Treatment & Mechanism of action & Examples \\
\hline Antacids & - Neutralize hydrochloric acid leading to increase in $\mathrm{pH}$ of the gastric contents & $\begin{array}{l}\text { - Sodium bicarbonate } \\
\text { - Calcium carbonate } \\
\text { - Magnesium carbonate } \\
\text { - Aluminum hydroxide } \\
\text { - Magnesium hydroxide } \\
\text { - Magnesium trisilicate }\end{array}$ \\
\hline Alginate & $\begin{array}{l}\text { - Precipitates to form a gel, which entraps carbon dioxide to develop foam } \\
\text { - The foam floats on the stomach contents, displaces the postprandial gastric } \\
\text { acid pocket, and physically blocks refluxate from entering the esophagus } \\
\text { - Alginates may also coat and protect the esophageal mucosa }\end{array}$ & $\begin{array}{l}\text { - Alginic acid (sodium alginate) } \\
\text { - Commonly formulated in combination with } \\
\text { antacids }\end{array}$ \\
\hline Histamine & - Gastrin secretion after a meal leads to histamine release & - Cimetidine \\
\hline $\begin{array}{l}\mathrm{H} 2 \text { receptor } \\
\text { antagonists } \\
\text { (H2RAs) }\end{array}$ & $\begin{array}{l}\text { - Stimulation of histamine } \mathrm{H} 2 \text { receptors leads to } \mathrm{HCl} \text { release via the hydrogen- } \\
\text { potassium ATPase }\left(\mathrm{H}^{+}-\mathrm{K}^{+}-\mathrm{ATPase}\right) \text { proton pump } \\
\text { - } \mathrm{H} 2 \mathrm{RAs} \text { are selective, competitive antagonists of histamine } \mathrm{H} 2 \text { receptors, } \\
\text { suppressing both basal and stimulated acid secretion produced by histamine } \\
\text { release }\end{array}$ & $\begin{array}{l}\text { - Famotidine } \\
\text { - Nizatidine } \\
\text { - Ranitidine }\end{array}$ \\
\hline $\begin{array}{l}\text { Proton pump } \\
\text { inhibitors (PPIs) }\end{array}$ & $\begin{array}{l}\text { - Irreversibly inactivates the active form of the proton pump }\left(\mathrm{H}^{+}-\mathrm{K}^{+}-\mathrm{ATPase}\right) \text {, } \\
\text { suppressing both stimulated and basal acid secretion produced by acetylcholine } \\
\text { and histamine release } \\
\text { - Accumulate at the luminal surface of the pump } \\
\text { - Prodrugs that require acidic conversion to the active species } \\
\text { - Acid labile and therefore in order to prevent premature activation their } \\
\text { formulations are commonly enteric coated } \\
\text { - As proton pump binding is irreversible, inhibition persists for up to } 36 \text { hours, } \\
\text { - Tall outlasting the plasma half-life of PPls (I-2 hours) } \\
\text { the inhibition of acid secretion to reach steady state }\end{array}$ & $\begin{array}{l}\text { - Esomeprazole } \\
\text { - Dexlansoprazole } \\
\text { - Lansoprazole } \\
\text { - Omeprazole } \\
\text { - Pantoprazole } \\
\text { - Rabeprazole }\end{array}$ \\
\hline
\end{tabular}

Note: Data from these studies. ${ }^{53-56}$

differences between alginate and H2RAs and alginate and PPIs was not statistically significant). Analysis found that the beneficial effect of alginate was superior regardless of whether the product tested also contained an antacid. The authors of the review suggested that alginate could be used for patients with mild GERD symptoms, thus reducing the need for acid suppressive therapy. ${ }^{53}$

Evidence also indicates that alginate is a bioadhesive allowing it to adhere to the esophageal mucosa and protect it from attack by acidic refluxate. Alginate adhesion has been shown to be durable for up to 1 hour after application. ${ }^{54}$

A small clinical trial found that alginate plus omeprazole $20 \mathrm{mg}$ increased the incidence of complete heartburn resolution more effectively than omeprazole alone. ${ }^{31}$ Another study indicated that addition of alginate for people with partial response to PPI therapy improved their quality of life (study was sponsor funded). ${ }^{32}$ Another study compared a proprietary suspension containing sodium alginate and sodium bicarbonate with omeprazole $20 \mathrm{mg}$ and found that the alginate/antacid combination was noninferior to omeprazole for the treatment of moderate, episodic heartburn (study was sponsor funded). ${ }^{33}$
A study comparing identical alginate/antacid doses but in two different dosage forms found that tablets and suspensions are equally effective at reducing gastric $\mathrm{pH} .{ }^{34}$

\section{Prokinetic agents}

Considering GERD is a disorder of intestinal motility and that delayed gastric emptying has been identified in some patients with GERD, it follows that prokinetic agents may be of benefit. However, evidence for cisapride in treating GERD in adults is conflicting and subsequent discovery of its cardiovascular toxicity led to it being withdrawn from the market. The newer generation 5-HT4 selective agonist prucalopride, which does not have the cardiovascular toxicity of cisapride, may prove effective for GERD; however, clinical trials are lacking. The use of metoclopramide and domperidone for GERD is equally controversial. ${ }^{54}$

\section{Acid suppressive therapy}

The 2011 gastroenterologist guidance for short-term treatment of GERD with over-the-counter PPIs was based on an expert review that concluded the following: ${ }^{26}$ 
- PPIs are more effective than H2RAs for the short-term (14 days) treatment of symptoms of GERD, with the clinical effect of short-term PPI lasting up to 10 weeks.

- PPIs produce stronger and longer lasting acid suppression than H2RAs (24 hours versus 3-15 hours, respectively) and are more effective than H2RAs for esophagitis.

- PPIs have convenient once daily dosing (while antacids are effective for symptoms they require multiple daily doses).

- Relief of symptoms with PPIs is rapid (onset of action is $\sim 1.5$ hours after administration, which is clinically significant after $1-3$ days).

- Efficacy and tolerability of PPIs results in better improvement in quality of life than H2RAs.

A meta-analysis investigating the effect of 14-day treatment with PPI compared to H2RA for NERD found that PPI has a significantly superior effect. Analysis also determined that PPI had a superior rate of symptomatic relief compared to H2RA. Compared to placebo, the overall rate of efficacy of PPI at relieving NERD symptoms was $51.4 \%$. Adverse event rates for PPI, H2RA, and placebo were not statistically different. ${ }^{55}$

PPI efficacy can be related to its ability to increase the $\mathrm{pH}$ of gastric acid. The optimal gastric environment for healing of reflux esophagitis is a $\mathrm{pH}$ above 4.0 for 15-21 hours per day and for healing of peptic ulcer is an optimal $\mathrm{pH}$ above 3.0 for $18-20$ hours per day ${ }^{35} \mathrm{H} 2 \mathrm{RAs}$ produce a gastric $\mathrm{pH}$ within the desired range for only $\sim 8$ hours. ${ }^{35}$

Comparing the efficacy of different PPIs is difficult as they are used at different dosing regimens; therefore, their relative potencies remain unclear. ${ }^{36}$

Esomeprazole (40 mg daily) seems to have the strongest effect on acid suppression. However, comparative studies across the PPI class indicate equivalent efficacy, which reflects their remarkably similar pharmacological properties. $^{35,36,56}$

A 2017 network meta-analysis found that esomeprazole $40 \mathrm{mg}$ improved the healing rate of erosive esophagitis to a greater extent than omeprazole $20 \mathrm{mg}$ at 4 and 8 weeks, lansoprazole $30 \mathrm{mg}$ at 4 and 8 weeks, rabeprazole $20 \mathrm{mg}$ at up to 8 weeks and pantoprazole $40 \mathrm{mg}$ at 4 weeks only. No significant differences existed when the PPIs other than esomeprazole $40 \mathrm{mg}$ were compared to each other. Esomeprazole $40 \mathrm{mg}$ also improved symptoms of heartburn to a greater extent than omeprazole $20 \mathrm{mg}$ and lansoprazole 30 $\mathrm{mg}$, but not pantoprazole $40 \mathrm{mg}$ or rabeprazole $20 \mathrm{mg} .{ }^{37}$

Pharmacists recommending PPIs without prescription for the short-term management of symptoms of GERD should commence therapy with the lowest effective dose, for a duration of 14 days. ${ }^{26}$ Holtmann et al recommend that patients who have GERD symptoms on three or more occasions per week can be recommended PPI therapy by pharmacists, but should also be referred to a doctor for assessment. ${ }^{26}$

Standard PPI therapy is effective in $90 \%-100 \%$ of people with mild symptoms; however, effectiveness decreases to $\sim 60 \%$ in people with the most severe disease. ${ }^{38}$ Evidence indicates that for maintenance therapy, low-dose PPI is as effective as high dose. ${ }^{54}$ But patients being treated with PPIs for severe erosive esophagitis, or disease resistant to standard PPI doses, experience better healing with once daily double doses of PPI (eg, $40 \mathrm{mg}$ esomeprazole versus $20 \mathrm{mg}$ ), or twice daily split dosing (eg esomeprazole $20 \mathrm{mg}$ twice daily). More recently, evidence indicates that a split dosing PPI regimen is superior to once daily double dosing, as it provides a bimodal distribution of plasma PPI concentration, which enables better inhibition of existing proton pumps over 24 hours and inhibition of newly produced pumps. ${ }^{38}$ PPI-resistant disease may also be improved by changing administration of the PPI to 1 hour before the largest meal of the day (usually dinner), to match the peak plasma concentration of the PPI (2-3 hours after oral administration), with the greatest expression of the proton pump. ${ }^{38}$ Trialing a different PPI in resistant disease may also be beneficial. ${ }^{38}$ The American Food and Drug Administration has approved all PPIs listed in Table 4 for the healing and maintenance of ERD and for NERD, except pantoprazole, which is not approved for NERD. ${ }^{35}$ PPIs are also effective for the management of peptic ulcer disease, Zollinger-Ellison syndrome (a rare neoplasm producing excess gastrin leading to excessive gastric acid production), and in combination with antibiotics for Helicobacter pylori eradication.

In the case of PPI refractory GERD, surgical approaches are available. Laparoscopic Nissen fundoplication (LNF wrapping of the fundus of the stomach around the esophagus) is the gold standard for the treatment of GERD refractory to medical management. A network meta-analysis found that LNF is superior to transoral incisionless fundoplication and PPI. ${ }^{57}$ Magnetic sphincter augmentation (MSA) involves placing a string of magnetic beads laparoscopically at the distal esophagus to provide increased sphincter tone. It is less invasive than LNF with minimal side effects. Metaanalysis indicates that the less invasive MSA is comparable to LNF in the short term; however, long-term data are still required..$^{39}$ Electrical sphincter stimulation also shows promise. Electrical stimulation increases the pressure of the LES, but the effect on TLESRs and the acid pocket is yet to be 
determined. Studies indicate that heartburn and regurgitation are both improved and that the intervention has the potential to provide a more uniform postoperative outcome than LNF. Larger, longer-term studies are still required to more clearly elucidate the outcomes. ${ }^{40}$

\section{Risks and benefits of long-term PPI therapy}

Since their introduction in the late 1980s, the use of PPIs has markedly increased. The reporting of adverse events and potential for inappropriate prescribing has also increased. A 2017 review by the American Gastroenterological Association outlined the potential risks associated with long-term use of PPIs including kidney disease, dementia, bone fracture, myocardial infarct, enteric infection, micronutrient deficiency, and gastrointestinal malignancy. The identified risks are class specific and commonly based on epidemiological evidence that is graded as being of low or very low quality. ${ }^{41}$ However, this evidence has led to a number of regulatory warnings being issued for long-term PPI use.

The review concluded that long-term PPI therapy is effective at preventing recurrence of complications of GERD including reflux esophagitis and esophageal stricture. However, the use of long-term PPIs for uncomplicated GERD is not necessary, as short-term use and on-demand use over the longer term is sufficient. ${ }^{41}$

Reduced gastric acid secretion subsequent to PPI therapy can theoretically lower the absorption of essential dietary nutrients that require an acidic environment for absorption, opening patients up to potential deficiency. Studies have indicated that PPI-induced deficiency is possible for iron, vitamin $\mathrm{B}_{12}$, and magnesium; however, evidence is not yet convincing. ${ }^{41,42}$ Long-term PPI therapy has also been shown to decrease calcium absorption, potentially increasing the risk of bone fracture. This was primarily a concern in older women taking calcium carbonate supplements. Low gastric $\mathrm{pH}$ is less likely to affect dietary calcium from dairy or calcium citrate supplements. People at risk of fracture should have their PPI therapy reassessed regularly; however, regular monitoring of bone mineral density in patients taking PPIs is not yet supported by evidence. ${ }^{41,42}$

Studies have shown that PPIs increase deposition of amyloid in rodent brains. This process is associated with the development of Alzheimer's disease in humans. Large epidemiological studies in older people have indicated an increased risk of dementia in people taking PPIs; however, a causal link is yet to be made..$^{41,42}$
Large epidemiological studies have indicated an increased risk of acute and chronic kidney disease in older people taking PPIs; however, a potential mechanism is not yet understood. Mainly, the data were collected retrospectively; therefore, some potential confounders may have been missed. ${ }^{41}$ However, the results indicate that monitoring of patients taking PPIs with risk factors for kidney disease may be warranted. ${ }^{42}$

Low gastric $\mathrm{pH}$ contributes to the gastric barrier against exposure of the bowel to ingested pathogenic organisms. It has long been considered that increased gastric $\mathrm{pH}$ resulting from PPI therapy may reduce this barrier function and lead to enteric infection. The focus of investigation of this possibility has been on Clostridium difficile, as increased gastric $\mathrm{pH}$ can contribute to increased proliferation of $C$. difficile spores. A number of studies have shown an increased incidence of $C$. difficile infection in people taking long-term PPIs, particularly in those also taking antibiotics. More recent evidence suggests that the association is actually related to marked alteration in gut microbiota caused by PPIs. Other potential enteric infections resulting from PPI therapy include Salmonella, Campylobacter, and small bowel overgrowth. ${ }^{41,42}$

The benefits of long-term PPI therapy include the potential for reduced progression of Barrett's esophagus (in patients with and without GERD symptoms) to esophageal adenocarcinoma (however, a 2017 meta-analysis found that PPIs did not protect against metaplasia or cancer $^{43}$ ) and reduced risk of nonsteroidal anti-inflammatory drug-induced mucosal damage and ulcer formation. ${ }^{41}$

\section{Deprescribing PPIs}

In light of potential adverse events associated with PPIs, concerns over inappropriate prescribing of PPIs has led to the development of deprescribing interventions in a number of settings. ${ }^{44,45}$ Deprescribing efforts focus on the use of PPIs in patients without a clinical indication, specifically in those taking PPIs chronically to treat uncomplicated GERD. Deprescribing can include ceasing short-term PPI therapy after 2-4 weeks or changing chronic dosing to ondemand dosing for uncomplicated GERD, but maintaining chronic dosing in complicated GERD, for example, Barrett's esophagus. While deprescribing PPIs has the benefit of reducing pill burden, a 2017 systematic review indicated that changing from chronic to on-demand prescribing of PPIs can increase the symptoms in patients with mild GERD. Therefore, a patient-centered approach must be taken when deprescribing PPIs. ${ }^{46}$ 


\section{PPI metabolism and drug interactions}

PPIs are rapidly metabolized in liver, primarily by the cytochrome CYP2C19 with CYP3A4 also contributing (except for lansoprazole and dexlansoprazole) and CYP2D6, CYP2C9, and CYP2C10 contributing to pantoprazole metabolism. The PPIs also exhibit some renal and biliary excretion. Genetic variation has led to the development of poor and extensive metabolizers of PPIs, which may explain differences in the response to PPIs. Hepatic impairment significantly increases the area under the curve and half-life of PPIs and may require additional monitoring. ${ }^{35,56}$

The clinical significance of most interactions with PPIs is low. ${ }^{47}$ The potential mechanisms for drug interactions with PPIs include decreased bioavailability of other drugs that require an acidic gastric $\mathrm{pH}$ for dissolution and effects on cytochrome function.

Some evidence does indicate that PPIs reduce blood levels of the anticoagulant dabigatran; however, the results were variable. ${ }^{48}$ Patients requiring antiplatelet therapy with clopidogrel with or without aspirin can be prescribed concomitant PPI to reduce the risk of antiplatelet-induced gastric ulceration. Clopidogrel requires activation by CYP2C19, which can be inhibited by concomitant PPIs. Observational data do suggest a greater risk of adverse cardiovascular outcomes in patients taking concomitant PPIs and clopidogrel; however, low-quality evidence from randomized clinical trials indicates no increased risk. ${ }^{49}$

The potential for adverse effects from other medicines can be increased when taken concomitantly with PPIs, requiring additional monitoring. These include risedronate (gastrointestinal adverse effects), ${ }^{49}$ metformin (all-cause mortality), ${ }^{49}$ antiretrovirals (HIV treatment failure and drug resistance) ${ }^{50}$ clozapine (neutropenia and agranulocytosis), ${ }^{51}$ levothyroxine (decreased absorption), ${ }^{52}$ and mycophenolate (decreased absorption). ${ }^{47}$

\section{Patient counseling}

Advice from pharmacists about over-the-counter treatment for intermittent symptoms of GERD includes: ${ }^{26}$

- Take acid suppressive therapy consistently at the same time each day, when symptoms are worse (ie, morning or evening)

- Take PPIs 1 hour before the largest meal (this allows the short half-life drug maximum time to inhibit the active proton pump)

- PPIs may take up to 3 days to reach their desired effect, with a maximum effect after 5 days
- PPIs may not be effective in all people with GERD symptoms

- Take over-the-counter PPIs for a maximum of 14 days

- Antacids and alginate can be used to treat breakthrough symptoms

- PPIs are generally well tolerated (common [1\%-10\%] adverse reactions include diarrhea, headache, nausea, abdominal pain, and constipation)

- Advise on diet and lifestyle adjustment

- Consult with a doctor if PPI therapy fails to improve symptoms, symptoms worsen, or concerning signs or symptoms occur.

\section{Summary}

GERD is common, particularly in people living in western countries. Treatment to manage symptoms is effective and can be accessed without prescription. Long-term treatment prescribed by a doctor has the potential to reduce serious GERD complications. Pharmacists play an important role in the management of GERD by helping patients to verify their diagnosis, referring them to a doctor for the assessment of alarming symptoms and recommending treatment including medication, diet, and lifestyle advice. Pharmacists can also advise patients on the safe and effective use of PPIs, help cease inappropriate use of PPIs, and address their adverse reactions and interactions with other medications.

\section{Disclosure}

The author reports no conflicts of interest in this work.

\section{References}

1. Kellerman R, Kintanar T. Gastroesophageal reflux disease. Prim Care. 2017;44(4):561-573.

2. Vakil N, van Zanten SV, Kahrilas P, Dent J, Jones R; Global Consensus Group. The Montreal definition and classification of gastroesophageal reflux disease: a global evidence-based consensus. Am J Gastroenterol. 2006;101(8):1900-1920.

3. Peery AF, Dellon ES, Lund J, et al. Burden of gastrointestinal disease in the United States: 2012 update. Gastroenterology. 2012;143(5): 1179-1187.

4. Okimoto E, Ishimura N, Morito Y, et al. Prevalence of gastroesophageal reflux disease in children, adults, and elderly in the same community. J Gastroenterol Hepatol. 2015;30(7):1140-1146.

5. Ness-Jensen E, Lindam A, Lagergren J, Hveem K. Changes in prevalence, incidence and spontaneous loss of gastro-oesophageal reflux symptoms: a prospective population-based cohort study, the HUNT study. Gut. 2012;61(10):1390-1397.

6. Iwakiri K, Kinoshita Y, Habu Y, et al. Evidence-based clinical practice guidelines for gastroesophageal reflux disease 2015. J Gastroenterol. 2016;51(8):751-767.

7. Rubenstein JH, Chen JW. Epidemiology of gastroesophageal reflux disease. Gastroenterol Clin North Am. 2014;43(1):1-14.

8. Harrison C, Henderson J, Miller G, Britt H. The prevalence of diagnosed chronic conditions and multimorbidity in Australia: a method for estimating population prevalence from general practice patient encounter data. PLoS One. 2017;12(3):e0172935. 
9. Bashashati M, Sarosiek I, McCallum RW. Epidemiology and mechanisms of gastroesophageal reflux disease in the elderly: a perspective. Ann N Y Acad Sci. 2016;1380(1):230-234.

10. Savarino E, de Bortoli N, De Cassan C, et al. The natural history of gastro-esophageal reflux disease: a comprehensive review. Dis Esophagus. 2017;30(2):1-9.

11. Pohl H, Welch HG. The role of overdiagnosis and reclassification in the marked increase of esophageal adenocarcinoma incidence. J Natl Cancer Inst. 2005;97(2):142-146.

12. Herregods TV, Bredenoord AJ, Smout AJ. Pathophysiology of gastroesophageal reflux disease: new understanding in a new era. Neurogastroenterol Motil. 2015;27(9):1202-1213.

13. Ness-Jensen E, Lagergren J. Tobacco smoking, alcohol consumption and gastro-oesophageal reflux disease. Best Pract Res Clin Gastroenterol. 2017;31(5):501-508.

14. Vasapolli R, Malfertheiner P, Kandulski A. Helicobacter pylori and nonmalignant upper gastrointestinal diseases. Helicobacter. 2016;21(Suppl 1):30-33.

15. Body C, Christie JA. Gastrointestinal diseases in pregnancy: nausea, vomiting, hyperemesis gravidarum, gastroesophageal reflux disease, constipation, and diarrhea. Gastroenterol Clin North Am. 2016;45(2):267-283.

16. Böhmer AC, Schumacher J. Insights into the genetics of gastroesophageal reflux disease (GERD) and GERD-related disorders. Neurogastroenterol Motil. 2017;29(2):13017.

17. Moraes-Filho JP. Refractory gastroesophageal reflux disease. Arq Gastroenterol. 2012;49(4):296-301.

18. Zografos GN, Georgiadou D, Thomas D, Kaltsas G, Digalakis M. Druginduced esophagitis. Dis Esophagus. 2009;22(8):633-637.

19. Tutuian R. Adverse effects of drugs on the esophagus. Best Pract Res Clin Gastroenterol. 2010;24(2):91-97.

20. Fletcher J, Wirz A, Young J, Vallance R, McColl KE. Unbuffered highly acidic gastric juice exists at the gastroesophageal junction after a meal Gastroenterology. 2001;121(4):775-783.

21. Wu J, Liu D, Feng C, et al. The characteristics of postprandial proximal gastric acid pocket in gastroesophageal reflux disease. Med Sci Monit. 2018;24:170-176.

22. Tytgat GN, McColl K, Tack J, et al. New algorithm for the treatment of gastro-oesophageal reflux disease. Aliment Pharmacol Ther 2008;27(3):249-256

23. Talley NJ. Functional dyspepsia: advances in diagnosis and therapy. Gut Liver. 2017;11(3):349-357.

24. Drossman DA, Hasler WL. Rome IV-functional GI disorders: disorders of gut-brain interaction. Gastroenterology. 2016;150(6): 1257-1261.

25. Yamawaki H, Futagami S, Wakabayashi M, et al. Management of functional dyspepsia: state of the art and emerging therapies. Ther $A d v$ Chronic Dis. 2018;9(1):23-32.

26. Holtmann G, Bigard MA, Malfertheiner P, Pounder R. Guidance on the use of over-the-counter proton pump inhibitors for the treatment of GERD. Int J Clin Pharm. 2011;33(3):493-500.

27. Souza RF. Reflux esophagitis and its role in the pathogenesis of Barrett's metaplasia. J Gastroenterol. 2017;52(7):767-776.

28. Panarelli NC. Other forms of esophagitis: it is not gastroesophageal reflux disease, so now what do I do? Surg Pathol Clin. 2017;10(4):765-779.

29. Smith CD. Esophageal strictures and diverticula. Surg Clin North Am. 2015;95(3):669-681.

30. Khan A, Kim A, Sanossian C, Francois F. Impact of obesity treatment on gastroesophageal reflux disease. World $J$ Gastroenterol. 2016;22(4):1627-1638.

31. Manabe N, Haruma K, Ito M, et al. Efficacy of adding sodium alginate to omeprazole in patients with nonerosive reflux disease: a randomized clinical trial. Dis Esophagus. 2012;25(5):373-380.

32. Reimer C, Lødrup AB, Smith G, Wilkinson J, Bytzer P. Randomised clinical trial: alginate (Gaviscon Advance) vs. placebo as add-on therapy in reflux patients with inadequate response to a once daily proton pump inhibitor. Aliment Pharmacol Ther. 2016;43(8):899-909.
33. Pouchain D, Bigard M, Liard F, Childs M, Decaudin A, McVey D.

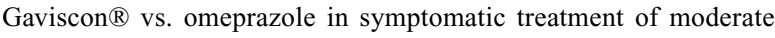
gastroesophageal reflux. A direct comparative randomised trial. BMC Gastroenterol. 2012;12:18.

34. Dettmar PW, Hampson FC, Taubel J, et al. The suppression of gastro-esophageal reflux by alginates. Int J Clin Pract. 2007;61(10): 1654-1662.

35. Strand DS, Kim D, Peura DA. 25 Years of proton pump inhibitors: a comprehensive review. Gut Liver. 2017;11(1):27-37.

36. Graham DY, TanselA. Interchangeable use of proton pump inhibitors based on relative potency. Clin Gastroenterol Hepatol. 2017 Epub Sep 28.

37. Li MJ, Li Q, Sun M, Liu LQ. Comparative effectiveness and acceptability of the FDA-licensed proton pump inhibitors for erosive esophagitis: a PRISMA-compliant network meta-analysis. Medicine (Baltimore). 2017;96(39):e8120.

38. Iwakiri K. Treatment strategy for standard-dose proton pump inhibitor-resistant reflux esophagitis. J Nippon Med Sch. 2017;84(5): 209-214.

39. Aiolfi A, Asti E, Bernardi D, et al. Early results of magnetic sphincter augmentation versus fundoplication for gastroesophageal reflux disease: systematic review and meta-analysis. Int J Surg. 2018;52: 82-88.

40. Kim SE, Soffer E. Electrical stimulation for gastroesophageal reflux disease: current state of the art. Clin Exp Gastroenterol. 2016;9:11-19.

41. Freedberg DE, Kim LS, Yang YX. The risks and benefits of long-term use of proton pump inhibitors: expert review and best practice advice from the American Gastroenterological Association. Gastroenterology. 2017;152(4):706-715.

42. Eusebi LH, Rabitti S, Artesiani ML, et al. Proton pump inhibitors: risks of long-term use. J Gastroenterol Hepatol. 2017;32(7):1295-1302.

43. Hu Q, Sun TT, Hong J, Fang JY, Xiong H, Meltzer SJ. Proton pump inhibitors do not reduce the risk of esophageal adenocarcinoma in patients with Barrett's esophagus: a systematic review and metaanalysis. PLoS One. 2017;12(1):e0169691.

44. Wilsdon TD, Hendrix I, Thynne TR, Mangoni AA. Effectiveness of interventions to deprescribe inappropriate proton pump inhibitors in older adults. Drugs Aging. 2017;34(4):265-287.

45. Naunton M, Peterson GM, Deeks LS, Young H, Kosari S. We have had a gutful: the need for deprescribing proton pump inhibitors. J Clin Pharm Ther. 2018;43(1):65-72.

46. Boghossian TA, Rashid FJ, Thompson W, et al. Deprescribing versus continuation of chronic proton pump inhibitor use in adults. Cochrane Database Syst Rev. 2017;3:CD011969.

47. Wedemeyer RS, Blume H. Pharmacokinetic drug interaction profiles of proton pump inhibitors: an update. Drug Saf. 2014;37(4): 201-211.

48. Stollberger C. Drug interactions with new oral anticoagulants in elderly patients. Expert Rev Clin Pharmacol. 2017;10(11):1191-1202.

49. Shamliyan TA, Middleton M, Borst C. Patient-centered outcomes with concomitant use of proton pump inhibitors and other drugs. Clin Ther. 2017;39(2):404-427.

50. McCabe SM, Smith PF, Ma Q, Morse GD. Drug interactions between proton pump inhibitors and antiretroviral drugs. Expert Opin Drug Metab Toxicol. 2007;3(2):197-207.

51. Wiciński M, Węclewicz MM, Miętkiewicz M, Malinowski B, Grześk E, Klonowska J. Potential mechanisms of hematological adverse drug reactions in patients receiving clozapine in combination with proton pump inhibitors. J Psychiatr Pract. 2017;23(2):114-120.

52. Ianiro G, Mangiola F, Di Rienzo TA, et al. Levothyroxine absorption in health and disease, and new therapeutic perspectives. Eur Rev Med Pharmacol Sci. 2014;18(4):451-456.

53. Leiman DA, Riff BP, Morgan S, et al. Alginate therapy is effective treatment for GERD symptoms: a systematic review and meta-analysis. Dis Esophagus. 2017;30(5):1-9.

54. Savarino E, Zentilin P, Marabotto E, et al. A review of pharmacotherapy for treating gastroesophageal reflux disease (GERD). Expert Opin Pharmacother. 2017;18(13):1333-1343. 
55. Zhang JX, Ji MY, Song J, et al. Proton pump inhibitor for non-erosive reflux disease: a meta-analysis. World J Gastroenterol. 2013;19(45): 8408-8419.

56. Shin JM, Sachs G. Pharmacology of proton pump inhibitors. Curr Gastroenterol Rep. 2008;10(6):528-534.
57. Richter JE, Kumar A, Lipka S, Miladinovic B, Velanovich V. Efficacy of laparoscopic nissen fundoplication vs transoral incisionless fundoplication or proton pump inhibitors in patients with gastroesophageal reflux disease: a systematic review and network meta-analysis. Gastroenterology. 2018;154(5):1298-1308.

\section{Publish your work in this journal}

Integrated Pharmacy Research and Practice is an international, peer-reviewed, open access, online journal, publishing original research, reports, reviews and commentaries on all areas of academic and professional pharmacy practice. This journal aims to represent the academic output of pharmacists and pharmacy practice with particular focus on integrated care. All papers are carefully

Submit your manuscript here: http://www.dovepress.com/integrated-pharmacy-research-and-practice-journal

peer reviewed to ensure the highest standards as well as ensuring that we are informing and stimulating pharmaceutical professionals. The manuscript management system is completely online and includes a very quick and fair peer-review system, which is all easy to use. Visit http://www.dovepress.com/ testimonials.php to read real quotes from published authors. 